\title{
Impact of elevated air velocity on subjective thermal comfort sensation under asymmetric radiation and variable airflow direction
}

\author{
Ferenc Kalmár \\ College professor, e-mail: fkalmar@eng.unideb.hu \\ University of Debrecen, Department of Building Services and Building Engineering \\ 4028 Debrecen, Ótemető str. 2-4, Hungary \\ Tel: +36 52 415155; Fax: +3652418643
}

\begin{abstract}
Buildings rarely have homogenous thermal indoor environments. Transparent building elements are one of the sources of thermal asymmetry. By using advanced personalized ventilation systems, the discomfort caused by radiation asymmetry may be reduced. A series of measurements involving 20 subjects was carried out under controlled environmental conditions to investigate subjective thermal comfort in the case of asymmetric radiation combined with the personalized ventilation. Analysis showed that the subjective thermal comfort sensation without a personalised ventilation system is similar to the calculated PMV. However, there is a significant difference between the responses of female and male participants. The advanced personalized ventilation system lowers the subjective thermal comfort sensation but does it differently for men and women. The skin temperatures of the hands of the women were significantly lower than that of the men. In the case of men, radiation asymmetry led to significant differences in the facial skin temperature, while in the case of the women, the differences in the facial skin temperature were not significant.
\end{abstract}

Keywords: asymmetric radiation; elevated air velocity; gender; personalized ventilation; skin temperatures; thermal comfort

\section{Introduction}

Although people spend $80-90 \%$ of their lives in buildings [1-3], their well-being in closed spaces strongly depend on the visual relationship with the outdoor environment. The transparency ratio of the building envelope should be chosen appropriately to provide daylighting, great views and appropriate thermal comfort simultaneously. Nowadays, architects prefer large transparent areas, which often become the source of thermal asymmetry. Shading elements may help reduce solar radiation, but may spoil the visual relation between indoor and outdoor. Although asymmetric radiation is considered a discomfort factor by the existing standards, long- and short-wave radiations are not treated separately [4]. Fanger et al. established the comfort limits of radiation asymmetry [5]. However, they focused on warm and cool opaque closing elements of closed spaces (i.e. the wall and ceiling). They determined the percentage of dissatisfied subjects as a function of the radiant temperature asymmetry and showed that there was no significant difference between the responses of men and women exposed to radiant asymmetry. Ghali et al. attempted to establish the effect of the asymmetric radiation field of stoves on thermal comfort [6]. To predict the overall thermal comfort and local thermal discomfort, they developed a bioheat model [6-7]. Their model agreed well with the experimentally reported data on local and mean skin temperatures under asymmetric radiation conditions and the corresponding heat loss from the human body [8]. Sokoi et al. 
assessed 35 thermal environmental conditions (air temperatures of 25.5 to $30.5^{\circ} \mathrm{C}$, radiation panel surface temperatures of 11.5 to $44.5^{\circ} \mathrm{C}$, humidity of $40 \% \mathrm{RH}$ to $50 \% \mathrm{RH}$, and a climatic chamber inlet velocity of less than $0.05 \mathrm{~m} / \mathrm{s}$.

In buildings with large transparent areas, during summer, people may be exposed simultaneously to short-wave and long-wave radiation [9]. Depending on the orientation and quality of the glazed elements, occupants may experience extreme thermal comfort conditions $[10,11]$. Arens et al. stated that direct warming by solar radiation may cause discomfort to occupants and will require substantial correction by the cooling system [12]. They developed the SolarCal online web-based tool, which can be used to compute an increase in mean radiant temperature (MRT) equivalent to shortwave gains from direct, diffuse, and indoorreflected radiation on a person. The direct solar radiation intensity depends on the geographical position of the building and the orientation of the glazed area. The fraction of the body exposed to solar radiation has to be established in order to compute the mean radiant temperature of a subject exposed to the solar radiation, [13-16].

In warm environments, elevated air speed may help improve the thermal comfort sensation [17]. However, the effect of simultaneous asymmetric radiation and elevated air velocity with temporal changes in the airflow direction is unknown.

The incident solar radiation depends on the position of the occupant in the room. Therefore, the causes of increase in the mean radiant temperature, which should be neutralised by an increase in air velocity, are numerous. Consequently, in a closed space, different locations require different air velocities. This criterion can be fulfilled by using personalised ventilation systems. It was shown that these systems might improve thermal comfort sensations in hot environments [18-21]. However, the airflow velocity has to be carefully chosen in order to avoid the sensation of draught. The interrelation between draughts and environmental parameters was investigated and presented by Fanger et al. [22], Griefahn et al. [23], and Toftum and Nielsen [24]. During these experiments, asymmetric radiation was avoided. Berglund and Fobelets analysed the subjective human response to low-level air currents and asymmetric radiation, but the aim of their research was to quantify the separate and additive effects of draughts and radiant asymmetry on sedentary people in neutral and cool environments [25].

For designers, understanding the influence of windows on thermal comfort is important for creating comfortable buildings. A complex research was carried out by Huizenga et al. in order to propose an analytical method for evaluating the impact of windows on thermal comfort [26]. They focused on the effect of window surface temperature on long-wave radiation heat exchange between the human body and the window and the effect of solar radiation transmitted by the window and absorbed by the body. With respect to solar radiation, only diffuse radiation was considered.

The present research aimed to investigate the subjective thermal comfort sensation under asymmetric radiation and to analyse the mitigation of the thermal comfort sensation by means of an advanced personalized ventilation system.

\section{Objectives and hypothesis}

The goal of this research was to analyse the time dependence of the thermal perception of college-age subjects under the effect of asymmetric radiation. Furthermore, by using an 
advanced personalized ventilation system, the effects of airflow with variable direction and elevated velocity on the subjective thermal sensation were investigated. Subjects had similar thermal backgrounds. Behavioural adaptation was not allowed during measurements.

It was presumed that subjects would not tolerate asymmetric radiation; that is, the subjective thermal comfort responses will increase in time. Furthermore, it was hypothesised that the elevated airflow velocity with variable direction will neutralise the negative effects of the asymmetric radiation.

\section{Methods and equipment}

\subsection{Climatic chamber and test room}

The Indoor Environmental Quality laboratory at the University of Debrecen is equipped with a climatic chamber. The test room $(2.50 \times 3.65 \times 2.55 \mathrm{~m})$ was set in this chamber. The test room had an "external" window $(90 \times 120 \mathrm{~cm})$. The window was double glazed (4-16-4 clear glass), with an air layer $\left(U=1.6 \mathrm{~W} \cdot \mathrm{m}^{-2} \cdot \mathrm{K}^{-1}, g=0.65\right)$. In the test room, all physical parameters of the ventilated air and the surface temperatures of the walls, floor, and ceiling can be controlled.

Asymmetric radiation was provided through the window of the test room by a GE Sportlight Tubular Clear metal halide lamp (Figure 1).
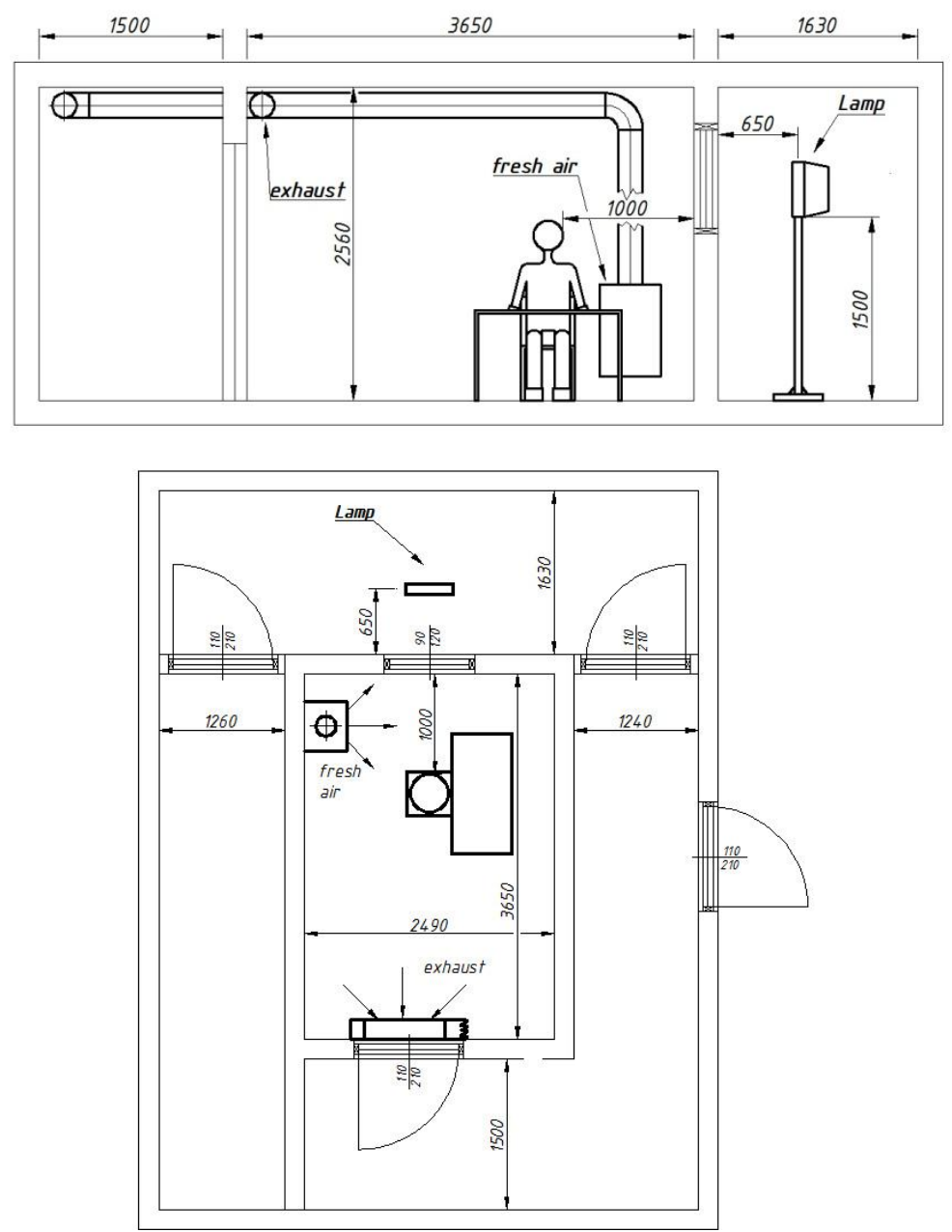

Figure 1. Measurement scheme (IEQ Laboratory) 
Hodder and Parsons used a similar radiation source for their experiments [27]. They investigated the effect of direct solar radiation on human thermal comfort in vehicle environments using three experiments designed to establish the relationship between solar radiation and thermal sensation in terms of radiation intensity level, spectral content, and the effect of different types of glazing. In the present study, incident radiation was provided from the left side of the occupant.

The colour temperature of the $1000 \mathrm{~W}$ lamp is $6000 \mathrm{~K}$. According to the spectral power distribution, emission was realized in the $200-800 \mathrm{~nm}$ wavelength range (short-wave radiation). Considering the run-up characteristics, the lamp reached the final and constant value of emission within $10 \mathrm{~min}$. The distance between the external glass surface and lamp was $0.65 \mathrm{~m}$, while that between the head of the occupant and the internal window surface was $1.0 \mathrm{~m}$. The lamp was fixed vertically at a height of $1.5 \mathrm{~m}$. The irradiance measured "indoor" at $1.1 \mathrm{~m}$ height on a vertical surface at a distance of $1.0 \mathrm{~m}$ from the window surface was 105 $\mathrm{W} \cdot \mathrm{m}^{-2}$ (warm sensation is generated by $35 \mathrm{~W} \cdot \mathrm{m}^{-2}$ absorbed thermal radiation [32]).

Fresh (outdoor) air $\left(50 \mathrm{~m}^{3} \cdot \mathrm{h}^{-1}, 100 \%\right.$ outdoor air) was provided continuously during the measurement by using an air terminal device installed in a corner above the floor. The exhaust slot was located under the ceiling.

\subsection{Instruments}

The indoor parameters were measured in each session of the experiment. The globe temperature, air temperature, relative velocity, and air velocity were measured using Testo Saveris data loggers. $\mathrm{CO}_{2}$ concentration was measured by a Testo 435 instrument. Airflows were measured with a KIMO AMI 300 instrument with a K75 airflow cone. Irradiance was measured with a Benning Sun2 instrument. Skin surface temperatures were measured using Tetso NTC probes, and the data were gathered by Testo T2 data logger. The accuracy of the probes is listed in Table 1.

Table 1. Accuracy of the probes and instruments

\begin{tabular}{|l|c|}
\hline Measured comfort parameter & Accuracy \\
\hline Globe temperature & $\pm 1^{\circ} \mathrm{C}$ \\
\hline Air temperature & $\pm 0.4^{\circ} \mathrm{C}$ \\
\hline Relative humidity & $\pm 2 \% \mathrm{RH}$ \\
\hline Air speed & $\pm(0.03 \mathrm{~m} / \mathrm{s}+5 \%$ of measured value $)$ \\
\hline Turbulence intensity & $\pm(0.03 \mathrm{~m} / \mathrm{s}+4 \%$ of measured value $)$ \\
\hline Airflow & $\pm(0.03 \mathrm{~m} / \mathrm{s}+3 \%$ of measured value $)$ \\
\hline $\mathrm{CO}_{2}$ concentration & $\pm(50 \mathrm{ppm} \mathrm{CO} 2 \pm 2 \%$ of measured value $)$ \\
\hline Irradiance & $\pm 5 \%$ of measured value \\
\hline Skin surface temperature & $\pm 0.2^{\circ} \mathrm{C}$ \\
\hline
\end{tabular}

\subsection{Subjects}

Knowing the statistical power and the effect sizes of measurements, indicating the effects of indoor environment quality on human health, thermal comfort, and productivity, is essential to obtain useful results. According to Lan and Lian [28], in the case of physiological 
measurement (subjective ratings of well-being), the effect size should be at least 0.658. In "between subject" design, the results of separate groups of subjects are compared, and hence, the total sample size should be 20 (10 subjects in one group) [28].

The participants in the measurements were 10 female and 10 male Hungarian college-age subjects. Subjects were students of mechanical engineering at the Faculty of Engineering, and hence were aware of the theoretical background of energy, heat exchange, temperature, SI units, etc. Considering the main goal of the measurements, subjects selected in both groups included persons using air conditioning systems and those using natural ventilation during summer. Furthermore, it was important that both groups included subjects who are sensible to draughts. The anthropometric data of the subjects involved in the measurements are presented in Table 2.

Table 2. Anthropometric data of the subjects

\begin{tabular}{|c|c|c|c|c|c|}
\hline Subjects & Data type & Age $[\mathrm{y}]$ & Weight $[\mathrm{kg}]$ & Height $[\mathrm{cm}]$ & $\mathrm{F}_{\mathrm{Du}}\left[\mathrm{m}^{2}\right]$ \\
\hline \multirow{2}{*}{ Female group } & Mean & 21.4 & 67.91 & 165.5 & 1.753 \\
\cline { 2 - 6 } & SD & 1.07 & 13.37 & 11.24 & 0.199 \\
\hline \multirow{2}{*}{ Male group } & Mean & 22.5 & 86.24 & 181.4 & 2.075 \\
\cline { 2 - 6 } & SD & 1.08 & 10.96 & 6.47 & 0.130 \\
\hline
\end{tabular}

$\mathrm{F}_{\mathrm{Du}}$ - body surface area calculated using the DuBois formula

Each group had five persons who used air conditioning systems and five who used natural ventilation during summer (this was necessary to avoid the potential failures caused by the thermal history of subjects). Subjects were asked about the indoor temperature preferred in summer and about their smoking habits. For both groups, the mean value of the preferred indoor temperatures was $24.5^{\circ} \mathrm{C}$. The female group had three smokers, while the male group had none (Table 3).

Table 3. Draught sensitivity, preferred indoor temperatures (summer), and smoking habits

\begin{tabular}{|c|c|c|c|}
\hline Subjects & $\begin{array}{c}\text { Draught sensitivity } \\
{[\%]}\end{array}$ & Preferred $t_{i},\left[{ }^{\circ} \mathrm{C}\right]$ & Smokers [\%] \\
\hline Female group & 40 & $24.5(\mathrm{SD}=1.27)$ & 30 \\
\hline Male group & 40 & $24.5(\mathrm{SD}=2.32)$ & 0 \\
\hline
\end{tabular}

\subsection{Experimental procedure}

Subjects were asked to arrive $30 \mathrm{~min}$ before the start of the measurements. They entered the anteroom of the IEQ laboratory where the temperature was set at $26^{\circ} \mathrm{C}$. This period of $30 \mathrm{~min}$ was considered as the time for acclimatisation to the environment. The blood pressure of the subjects was measured using an Omron M10-IT monitor. During the measurements, the subjects sat at the desk in the test room (Figure 1). They were unaware of the experimental schedule and indoor parameters. During measurements, the clothing thermal insulation was 0.5 clo (ISO 9920:2007, Men: underpants, shirt with short sleeves, light trousers, light socks, and shoes; Women: bra, panty, shirt with short sleeves, skirt, sandals), and the activity level was $70 \mathrm{~W} \cdot \mathrm{m}^{-2}$ (sedentary activity; ISO $8996: 2004$ ). Testo surface temperature probes were affixed on the hands and on the faces (left and right sides) of the subjects. Skin surface temperatures were registered every $10 \mathrm{~s}$. 
Four series of measurements were carried out. The duration of one session was $90 \mathrm{~min}$. One session was divided into three periods of $30 \mathrm{~min}$ each. The first two periods were similar for each measurement session. In the first $30 \mathrm{~min}$, the indoor parameters were set to assure a mean radiant temperature and an air temperature of $26{ }^{\circ} \mathrm{C}$. The relative humidity was set to $50 \%$. The window was covered on the outer side with a $20-\mathrm{mm}$ thick cross-laminated timber board (white coloured). After $20 \mathrm{~min}$, the metal halide lamp was switched on. This operation had no effect on the indoor parameters in the test room. After $30 \mathrm{~min}$, the cross-laminated timber board was removed. In the next $30 \mathrm{~min}$, the test room was operated with an air change rate and air temperature similar to the previous period, but because of the external radiation source, the mean radiant and air temperatures increased. The indoor micro-environmental parameters for the last $30 \mathrm{~min}$ were different for each measurement session. In the basic case, nothing was changed from the conditions of the second period (i.e. radiation, air temperature, and air change rate in the two periods were identical). For the other three sessions the advanced personalized ventilation system (ALTAIR) was in operation. The ALTAIR system is based on the variation in airflow direction. Ventilated air was introduced sequentially from three directions (left-fron-right), and the air jet direction was continuously changed at a set time step. The air terminal devices were placed on a horizontal plane at a height of $1.1 \mathrm{~m}$ from the floor. The airflow was circulated through desk-built-in air channels and was directed alternately from the left, front, and right sides onto the occupant. By changing the step of the airflow direction, different turbulence intensities were realized. During the measurements in the last three sessions, the circulated airflow realized by ALTAIR was $20 \mathrm{~m}^{3} \cdot \mathrm{h}^{-1}$. The air velocity around the head was $0.48 \mathrm{~m} \mathrm{~s}^{-1}$. The turbulence intensities in the last three sessions were $\mathrm{Tu}_{30}=18.8 \%$ (30 s time step of changing the airflow direction), $\mathrm{Tu}_{20}=19.1 \%$ (20 s time step), and $\mathrm{Tu}_{10}=20.6 \%$ (10 s time step). Using the TESTO 480 instrument, the air and globe temperatures, relative humidity, and air velocity were measured. The PMV was calculated for the first and last 30 minutes, since in these periods steady state indoor environmental conditions can be assumed. In Figure 2, the variations in the air and mean radiant temperatures are presented (without subjects in the test room). The parameters were measured at a distance of $1.0 \mathrm{~m}$ from the window surface and at a height of $1.1 \mathrm{~m}$ from the floor. The calculated PMV was 0.14 for the first 30 minutes and 0.80 (without ALTAIR) and 0.52 (with ALTAIR) for the last 30 minutes.
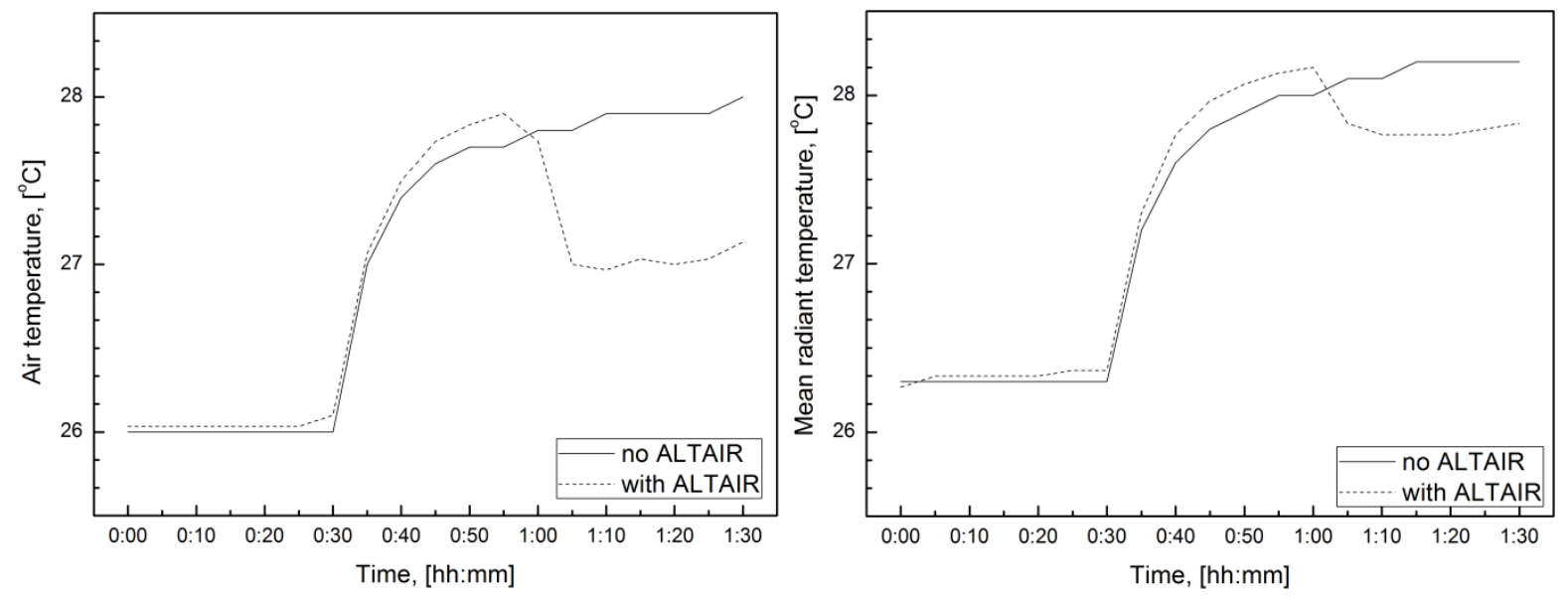

Figure 2. Indoor temperatures in the test room (without subjects in the test room) 
Small differences exist between the temperatures recorded in different sessions. These temperature differences are generated by the hysteresis of the control elements of the heating and ventilation systems of the test room (they are lower than the accuracy of the probes and measuring instruments). Furthermore, the time step of the changes in airflow direction (scheduled for the last three experiment sessions) has no significant effect on the calculated PMV.

During the measurement sessions, the subjects were asked to complete a short questionnaire repeatedly at 10-min intervals:

Q1. Evaluate the indoor environment on the following scales (Figure 3):

a) Mark the odour intensity in the room on the 6-point scale.

b) Mark your thermal comfort sensation on the 7-point thermal comfort scale.

c) Mark the acceptability of the environment on the 3-point scale.
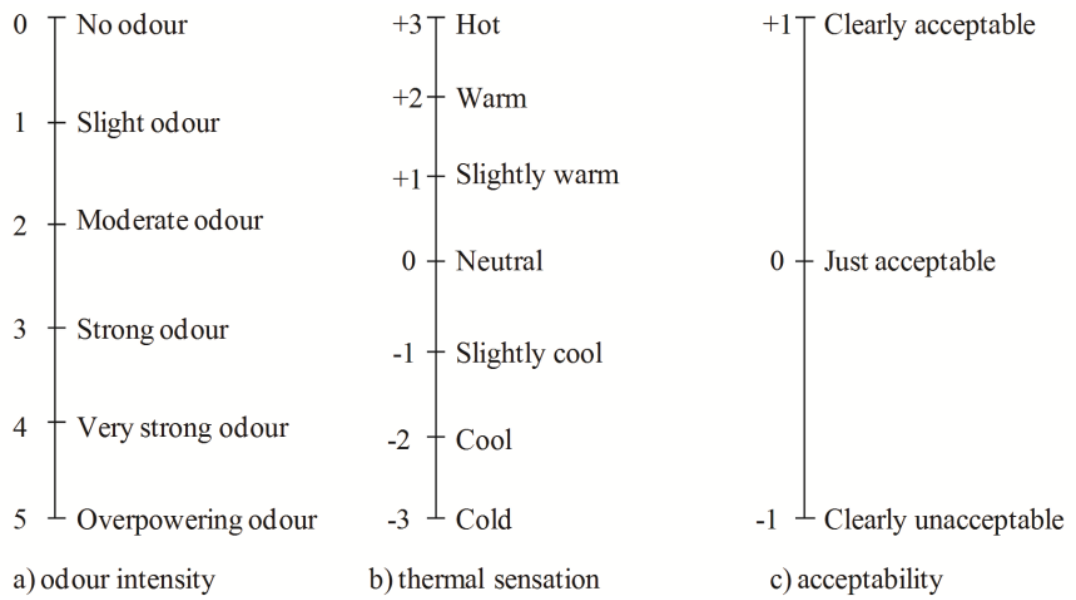

Figure 3. Scales for indoor environment quality evaluation

Q2. Is the air velocity acceptable?

Yes

No

If not, what change should be made in the air velocity?

Increase

Decrease

Q3. Do you feel a draught?

Yes

No

If your answer is Yes, please specify if the draught is

$$
\text { embarrassing not embarrassing }
$$

If your answer to Q3 is Yes, please specify the body segment(s) where you feel a draught:

head neck arms back legs ankles

Q4. Are you content with the indoor air freshness $\left(\mathrm{CO}_{2}\right.$ concentration)?

$$
\text { Yes No }
$$

Q5. Are you content with the indoor surface temperatures?

Yes

No

If not, what should be done?

floor temperature:

increase decrease

ceiling temperature:

increase decrease

wall temperature:

increase

decrease

(underline the wall whose temperature should be changed: front, back, left, and right)

The window was considered as a part of the left wall. 


\section{Results and discussion}

The deterministic model of PMV was developed for steady state indoor conditions. According to standard ISO 7730 three types of non-steady-state conditions can occur: temperature cycles, temperature drifts or ramps, and transients. Temperature cycles can occur due to the control of the temperature in a space. If the peak-to-peak variation is less than $1.0 \mathrm{~K}$, there will be no influence on the comfort and the recommendations for steady-state may be used. If the rate of temperature change for drifts or ramps is lower than $2.0 \mathrm{~K} / \mathrm{h}$, the methods for steady-state variation apply. After an up-step in operative temperature, the new steady-state thermal sensation is experienced immediately, thus the PMV-PPD can be used to predict comfort. Following a down-step in operative temperature, the thermal sensation drops at first to a level beneath the one predicted by PMV, then increases and reaches under steady-state conditions the steady-state level after approximately $30 \mathrm{~min}$.

Because of the asymmetric radiation there is an operative temperature increase of $1.8 \mathrm{~K}$ in the second session of the experiments, but $1.4 \mathrm{~K}$ is realized in the first 10 minutes of the session. In the last sessions the operative temperature decreased due to the higher air velocity, but the decrease is lower than $0.5 \mathrm{~K}$.

As a consequence of the variation of the indoor environmental parameters, the periods of the measurement sessions has to be analysed separately: the first and the last period can be considered having steady state environmental conditions, while the second period has unsteady state environmental conditions. Measurements have proven that the time step of the air flow direction changing has no effect on the subjective thermal comfort, so the last period will be presented considering only two cases: without and with ALTAIR PV system.

\subsection{Skin temperatures}

Skin temperature was measured every $10 \mathrm{~s}$, and the data were registered by data loggers. In one session, 2160 skin temperature data were registered by four data loggers (right and left hands and right and left sides of the face). The skin temperatures are presented in Figure 4-6 for analysed groups. These diagrams show the skin temperatures for every $5 \mathrm{~min}$. For time moment 0:00, each skin temperature is the average of 10 values (the number of subjects). All the other skin temperatures in the diagram represent the average of 300 values ( 30 values in 5 min $\times$ number of subjects).
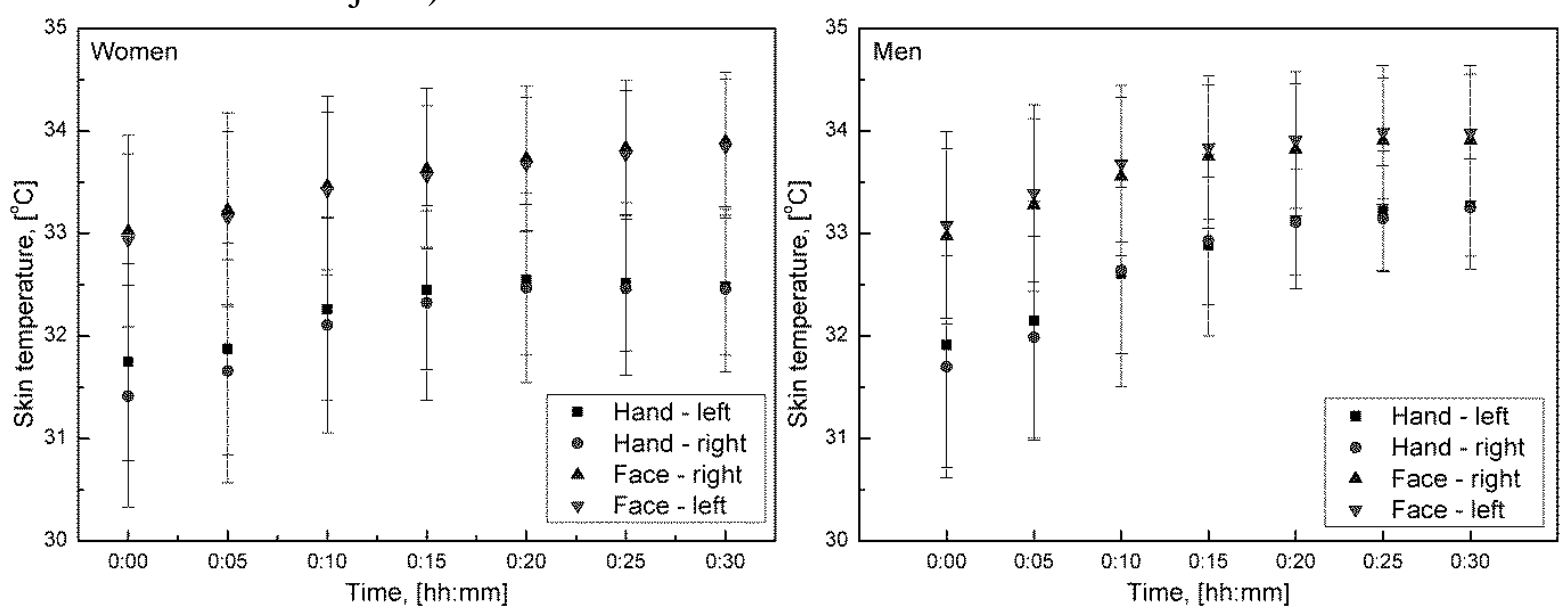

Figure 4. Skin temperatures during the first period (steady state) 

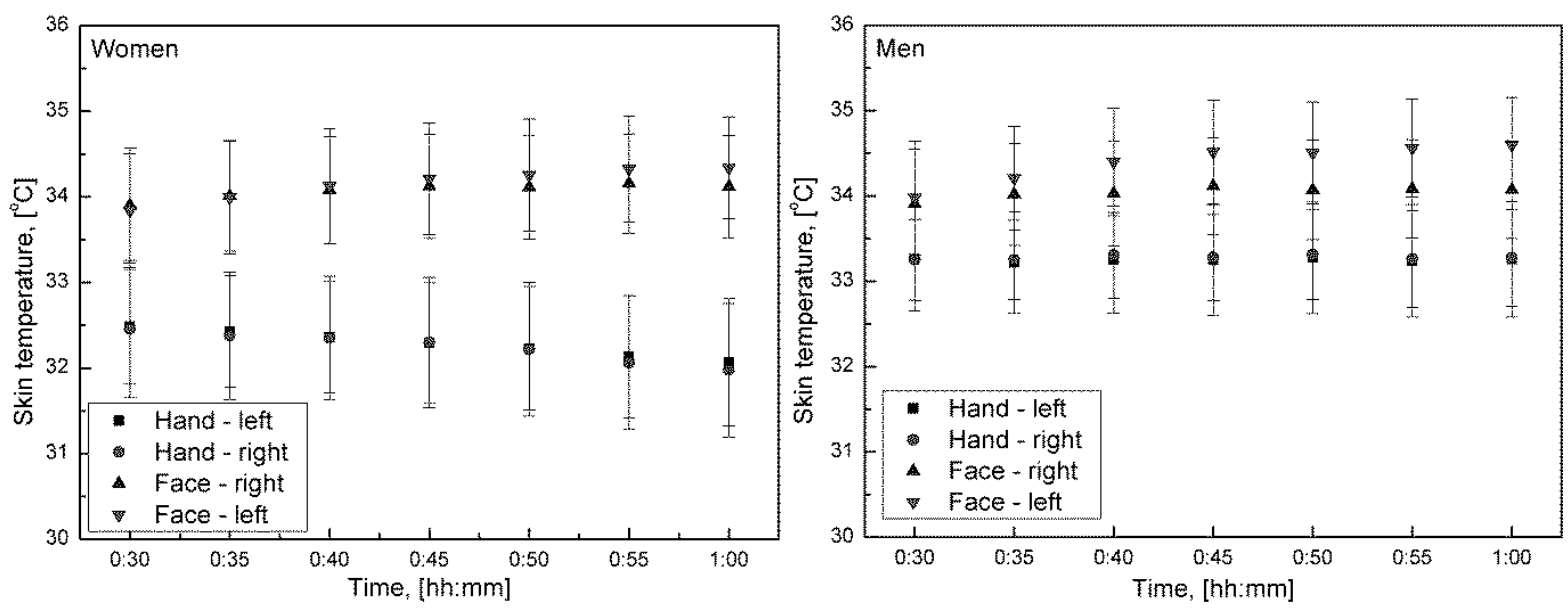

Figure 5. Skin temperatures during the second period (unsteady state)

The difference between the facial skin temperatures of women and men in the first hour of measurements is interesting. For the women, the skin temperatures of the hands reach the maximum value after $20 \mathrm{~min}$. Thereafter, a decrease is observed in spite of switching on the asymmetric radiation heat source and the increase in the air and mean radiant temperatures. At the same time, the temperatures of the left and right sides of the face increased. However, there was no significant difference between these temperatures (the irradiance was provided from the left side). In contrast, for the men, the temperatures of the hands remained almost constant after the first $30 \mathrm{~min}$, and there was a significant difference between the skin temperatures on the left and right sides of the face in the last $30 \mathrm{~min}$ of the measurement sessions. These temperature values suggest that the subjective thermal comfort sensation votes of the men group will be higher than the subjective thermal votes of the women group. The skin temperatures for the last period of each session are presented in Figure 6.

For the last periods of the measurement sessions, there was no significant difference between the temperatures of the hands both for women and men groups. Moreover, there was no significant difference between the skin temperatures of the hands or faces for different operation modes of the ALTAIR personalized ventilation equipment. However, the facial skin temperatures were significantly different between the cases with and without ALTAIR. Furthermore, there is a significant difference between the hand skin temperatures of women and men groups. The time step of changes in airflow direction has no effect on the skin temperatures. The subjective votes for both groups in the last $30 \mathrm{~min}$ are expected to decrease.
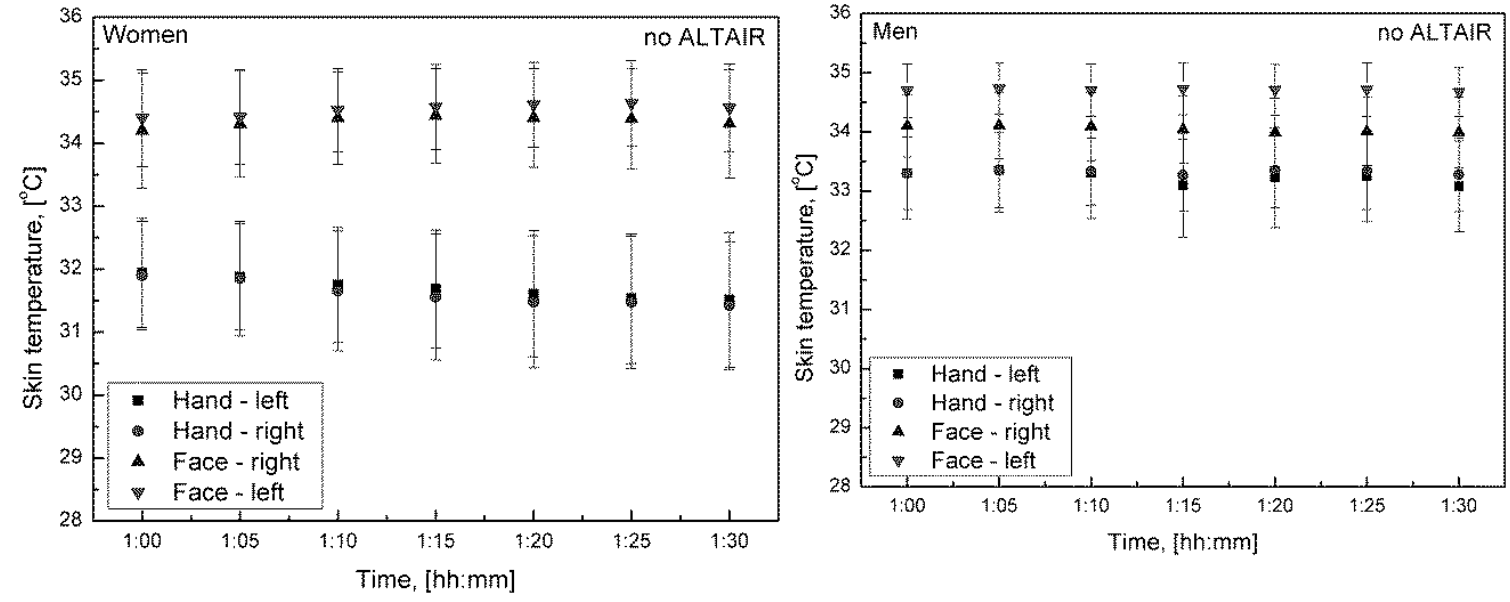

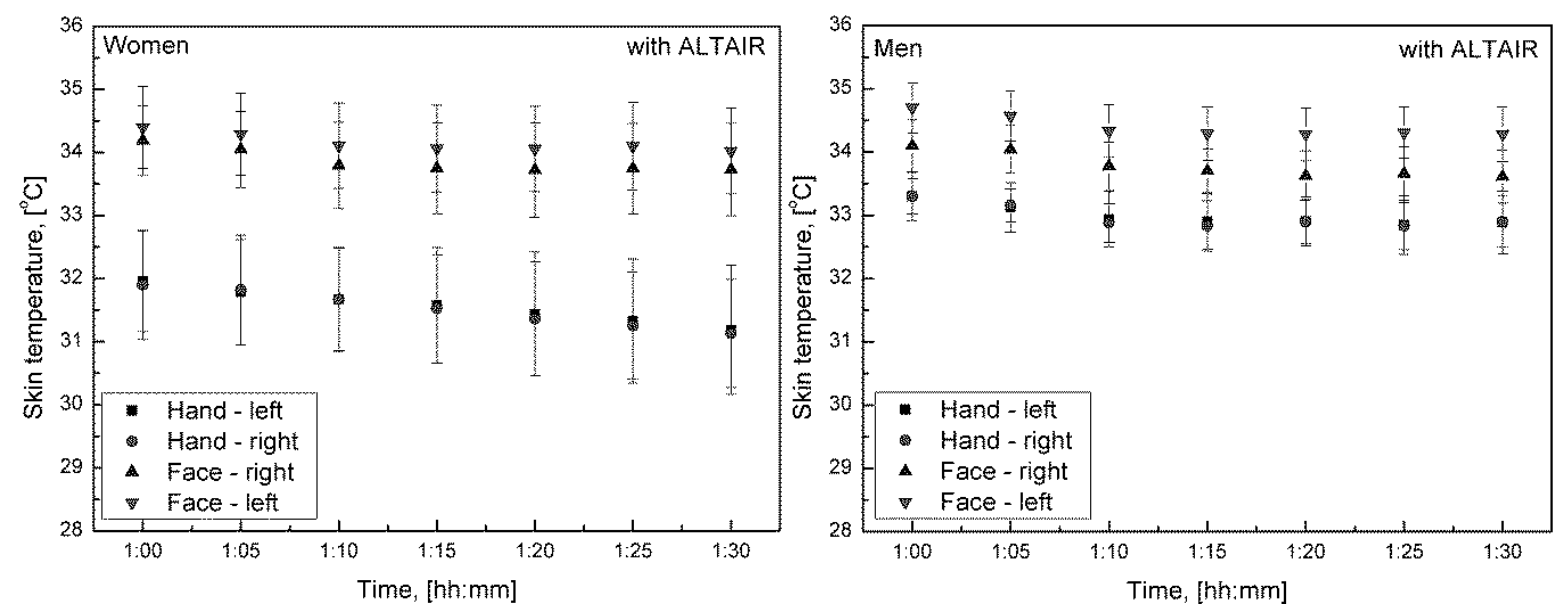

Figure 6. Skin temperatures for the third periods of measurements (steady state)

\subsection{Thermal sensation}

The subjective thermal comfort votes for each measurement session are presented in Figure 7. Acclimatisation to the environment during the first $30 \mathrm{~min}$ of each session can be noted. The asymmetric radiation led to higher subjective thermal comfort responses, but the increase is small (approximately 0.3). It is interesting that the thermal responses increased (not significantly, but the values are higher) in the last period of the first session. That is, in the case of these boundary conditions, acclimatisation to asymmetric radiation did not occur.

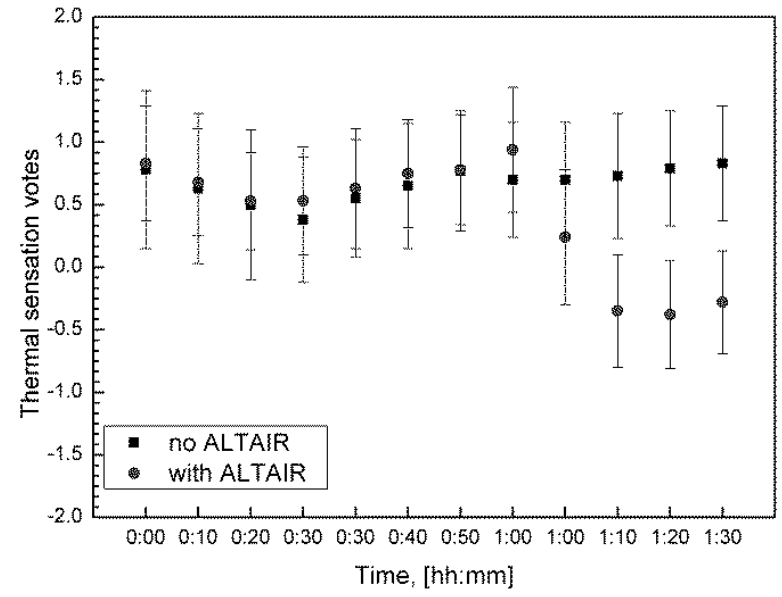

Figure 7. Subjective thermal comfort sensation

In the case of first session and the first two periods of the other sessions, there is good agreement between the subjective answers and the calculated PMV. However, there is a significant difference between the calculated PMV (0.52) and subjective thermal comfort responses in the last periods of each session (the average value is approximately -0.3 ). A strong cooling effect was achieved by moving the air around the head of the occupant. During the experiments, the air temperature at the inlet section of ALTAIR was measured and was found to be lower than the temperature around the head of the occupants by $0.1-0.2^{\circ} \mathrm{C}$ (this is caused by the vertical temperature differences as the inlet orifice of ALTAIR is placed $30 \mathrm{~cm}$ above the floor). Statistical analysis of each group was performed at the end of each period of the measurement sessions (Table 4). 
Table 4. Statistical analysis of subjective thermal comfort responses

\begin{tabular}{|l|c|c|c|c|}
\hline \multicolumn{1}{|c|}{ Group_time_session } & Sample size & Mean & Standard Deviation & SE of Mean \\
\hline Women_0:30 & 40 & 0.5425 & 0.62466 & 0.09877 \\
\hline Women_1:00 & 40 & 1.0175 & 0.61556 & 0.09733 \\
\hline Men_0:30 & 40 & 0.3625 & 0.46668 & 0.07379 \\
\hline Men_1:00 & 40 & 0.6375 & 0.50621 & 0.08004 \\
\hline Women_1:30_No ALTAIR & 10 & 1.14 & 0.52536 & 0.16613 \\
\hline Women_1:30_30 s & 10 & -0.16 & 1.04371 & 0.33005 \\
\hline Women_1:30_20 s & 10 & -0.25 & 0.58926 & 0.18634 \\
\hline Women_1:30_10 s & 10 & -0.25 & 0.58926 & 0.18634 \\
\hline Men_1:30_No ALTAIR & 10 & 0.52 & 0.49844 & 0.15762 \\
\hline Men_1:30_30 s & 10 & -0.28 & 0.68767 & 0.21746 \\
\hline Men_1:30_20 s & 10 & -0.3 & 0.42164 & 0.13333 \\
\hline Men_1:30_10 s & 10 & -0.4 & 0.45947 & 0.1453 \\
\hline
\end{tabular}

The results of the ANOVA test showed that for the women group, the differences in the means registered at $30 \mathrm{~min}$ and 1:00 h are significantly different. Furthermore, the difference in the means between the women and men groups at 1:00 $\mathrm{h}$ is significantly different. There is no significant difference between the responses of the men group for the first two periods of each session. As expected, the differences between the means of each group registered in the first session (no ALTAIR) and the means of all other sessions with ALTAIR in operation are significant. There is no significant difference between the responses in the case of different operation methods of ALTAIR.

\subsection{Odour intensity}

No special odorants were used in the experiments to evaluate their effects. The building materials or the installed equipment acted as sources of pollutants in the test room. The aim was to avoid causing of discomfort to the occupants by possible sources of odours. Subjects evaluated the odour intensity on a 6-point scale (Figure 3). The mean values of responses are shown in Figure 8.

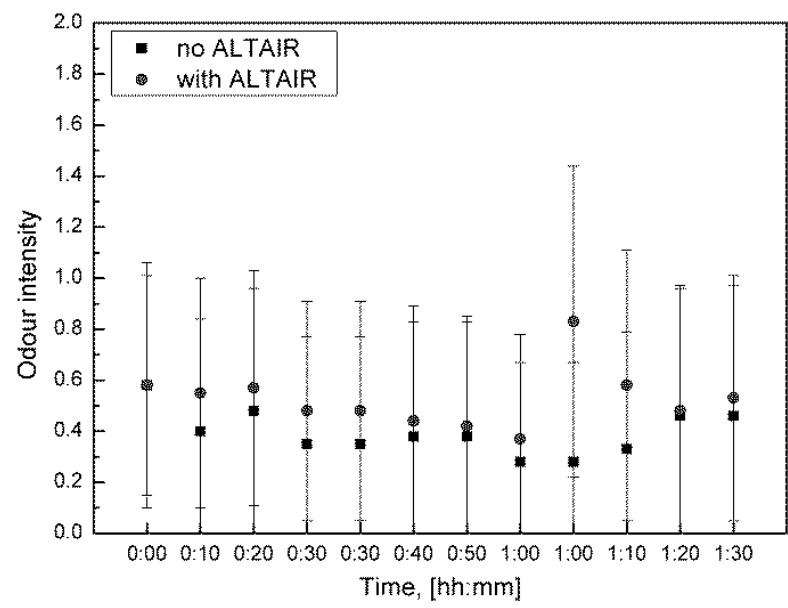

Figure 8. Evaluation of odour intensity

There was no significant difference between the responses for the first two periods of each session. Occupants evaluated the odour intensity between 0 and 1 (no odour-slight odour). 
However, upon starting the operation of ALTAIR personalized ventilation equipment, a significant increase in odour intensity evaluation was observed. Because of adaptation, odour intensity evaluation decreased for the last $20 \mathrm{~min}$ of the measurements.

\subsection{Air freshness}

Haldi and Robinson [29] already described the hypothesis of Leaman and Bordass [30] with regard to the interrelation between different aspects of environmental comfort. They presumed that under-performance in one aspect of environmental comfort might negatively affect other aspects.

The $\mathrm{CO}_{2}$ concentration in the test room during the four sessions is shown in Figure 9 (for each moment, 80 values were considered-20 subjects $\times 4$ sessions). The $\mathrm{CO}_{2}$ concentration ranged 580-710 ppm. In spite of the low $\mathrm{CO}_{2}$ concentration in the indoor air (the air change rate was $2.15 \mathrm{~h}^{-1}$ ), some subjects were dissatisfied with the freshness (Table 5). However, in the periods when ALTAIR was in operation, the number of occupants who were discontent with the air freshness decreased. Taking into account the fact that the subjective thermal sensation decreased significantly in the last period of sessions 2-4, the reduction in the number of persons dissatisfied with air freshness agrees well with previous research results [31].

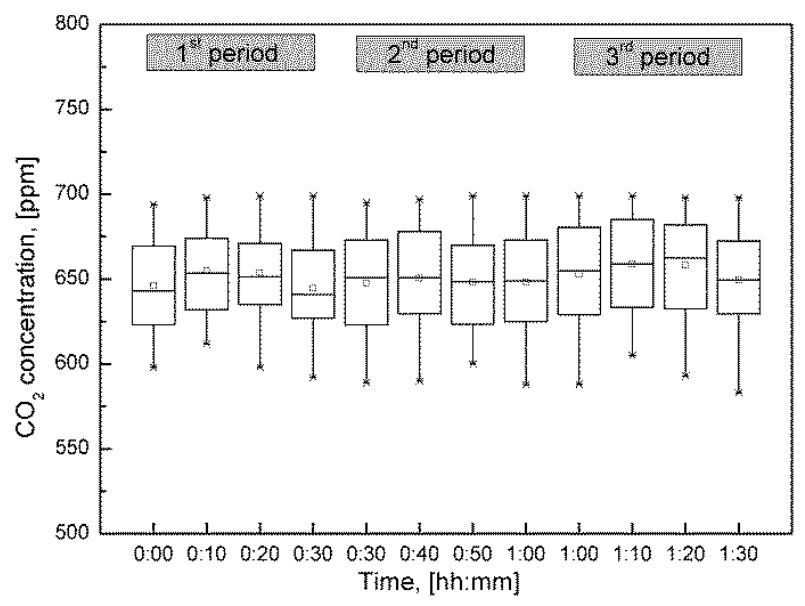

Figure 9. $\mathrm{CO}_{2}$ concentration in the test room

Table 5. Subjects dissatisfied with the air freshness

\begin{tabular}{|c|c|c|c|c|c|c|c|c|c|c|c|c|c|}
\hline \multirow{2}{*}{ Session } & \multirow{2}{*}{ Gender } & \multicolumn{12}{|c|}{ Time } \\
\hline & & 0:00 & $0: 10$ & $0: 20$ & $0: 30$ & $0: 30$ & $0: 40$ & $0: 50$ & $1: 00$ & $1: 00$ & $1: 10$ & $1: 20$ & $1: 30$ \\
\hline \multirow{2}{*}{1.} & Women & 7 & 3 & 3 & 4 & 4 & 3 & 3 & 3 & 3 & 5 & 3 & 3 \\
\hline & Men & 6 & 6 & 4 & 4 & 4 & 4 & 5 & 3 & 3 & 3 & 2 & 3 \\
\hline \multirow{2}{*}{2.} & Women & 5 & 3 & 4 & 3 & 3 & 2 & 2 & 2 & 2 & 0 & 0 & 0 \\
\hline & Men & 3 & 3 & 2 & 3 & 3 & 4 & 4 & 4 & 4 & 3 & 2 & 2 \\
\hline \multirow{2}{*}{3.} & Women & 3 & 3 & 3 & 4 & 4 & 2 & 3 & 3 & 2 & 1 & 1 & 1 \\
\hline & Men & 3 & 3 & 3 & 3 & 3 & 3 & 4 & 5 & 4 & 2 & 2 & 2 \\
\hline \multirow{2}{*}{4.} & Women & 5 & 4 & 3 & 3 & 3 & 2 & 3 & 3 & 2 & 0 & 0 & 0 \\
\hline & Men & 3 & 3 & 3 & 2 & 2 & 2 & 2 & 4 & 2 & 1 & 0 & 0 \\
\hline
\end{tabular}




\subsection{Air velocity and draught}

During total volume ventilation, the air velocity around the head of the seated occupant was $0.02 \pm 0.01 \mathrm{~m} / \mathrm{s}$. When the ALTAIR equipment was switched on, the air velocity around the head increased to $0.48 \mathrm{~m} \mathrm{~s}^{-1}$. Furthermore, the time step of the change in the airflow direction was $30 \mathrm{~s}$ in the $2^{\text {nd }}$ session, $20 \mathrm{~s}$ in the $3^{\text {rd }}$ session, and $10 \mathrm{~s}$ in the $4^{\text {th }}$ session. This variation in the direction of the air velocity vector induced a small variation in the turbulence intensity. In both groups, four persons were sensible to draught. The air and mean radiant temperature increased by 1.8-2 $\mathrm{K}$ in the first hour of the measurements (Figure 2). For the first period of measurements sessions, few subjects were expected to prefer higher air velocity. For the second period of measurements, because of the asymmetric radiation, the number of persons preferring higher air velocity was expected to increase. For the last period, many subjects were expected to prefer low air velocity. Moreover, a high percentage of subjects were expected to perceive a draught. In warm environments, the draught may help to improve thermal comfort sensation, and hence, it was expected that some subjects who perceived draught would not experience discomfort.

The percentage of subjects satisfied with the air velocity was around $90 \%$ for both groups without the ALTAIR PV system. The number of satisfied persons decreased in the last period of measurements (50-60\%). However, there is a difference between the groups with regard to the time step of change of airflow direction (women accepted the 10-s time step better). In the first two periods, all the dissatisfied subjects preferred an increase in the air velocity. In the last 30 min of each session, all the dissatisfied subjects preferred a decrease in the air velocity. In the first one hour of each session, practically nobody perceived draught. The number of subjects who perceived draught in the last $30 \mathrm{~min}$ is presented in Table 6.

Table 6. Number of subjects who perceived draught and the number of subjects who found the draught embarrassing

\begin{tabular}{|c|c|c|c|c|c|c|c|c|c|}
\hline \multirow{2}{*}{ Session } & \multirow{3}{*}{ Gender } & \multicolumn{3}{|c|}{ Draught - perceived } & \multicolumn{4}{|c|}{ Draught - embarrassing } \\
\cline { 3 - 11 } & & $1: 00$ & $1: 10$ & $1: 20$ & $1: 30$ & $1: 00$ & $1: 10$ & $1: 20$ & $1: 30$ \\
\hline \multirow{2}{*}{2.} & Women & 4 & 6 & 7 & 7 & 3 & 4 & 3 & 5 \\
\cline { 2 - 11 } & Men & 8 & 10 & 10 & 10 & 1 & 5 & 4 & 4 \\
\hline \multirow{2}{*}{3.} & Women & 3 & 5 & 7 & 7 & 0 & 2 & 3 & 4 \\
\cline { 2 - 11 } & Men & 4 & 8 & 7 & 7 & 1 & 2 & 3 & 3 \\
\hline \multirow{2}{*}{4.} & Women & 4 & 4 & 4 & 4 & 1 & 2 & 2 & 2 \\
\cline { 2 - 10 } & Men & 5 & 4 & 6 & 6 & 1 & 1 & 3 & 3 \\
\hline
\end{tabular}

\subsection{Asymmetric radiation and overall acceptance of the indoor environment}

The overall acceptance of the environment was expected to be close to 1 (according to the scale presented Figure 3) in the first $30 \mathrm{~min}$ in all sessions. The acceptance was expected to decrease below 0 in the second period of each session. The acceptance was expected to decrease below 0 (assuming that in case of asymmetric radiation, acclimatization is excluded) in the last period of session 1. Moreover, it was hypothesised that most subjects will prefer reduction of the radiation. In the last period of sessions $2-4$, the increased air velocity was presumed to neutralise the discomfort caused by asymmetric radiation, and the acceptance of 
the indoor environment was expected to increase over 0 . The responses are presented in Figure 10 .

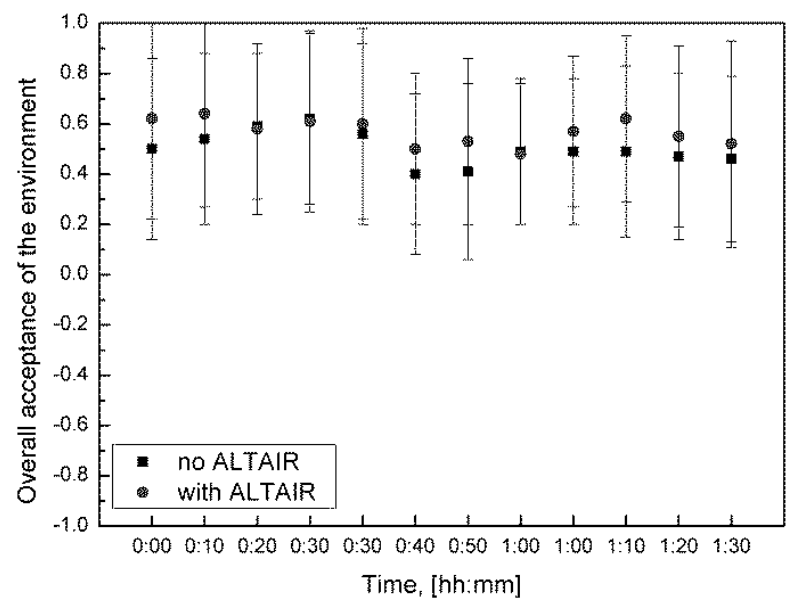

Figure 10. Acceptance of the environment

It is interesting that $105 \mathrm{~W} \cdot \mathrm{m}^{-2}$ asymmetric radiation $\left(35 \mathrm{~W} \cdot \mathrm{m}^{-2}\right.$ absorbed heat leads to warm sensation, [32]), and in the last period, the elevated air velocity had no effect on the overall acceptance of the environment. The responses show no significant differences between the groups. The number of subjects contented with the temperature of the surrounding surfaces is presented in Table 7.

Table 7. Subjects satisfied with the surrounding surface temperatures

\begin{tabular}{|c|c|c|c|c|c|c|c|c|c|c|c|c|c|}
\hline \multirow{2}{*}{ Session } & \multirow{2}{*}{ Gender } & \multicolumn{10}{|c|}{ Time } \\
\cline { 3 - 17 } & & $0: 00$ & $0: 10$ & $0: 20$ & $0: 30$ & $0: 30$ & $0: 40$ & $0: 50$ & $1: 00$ & $1: 00$ & $1: 10$ & $1: 20$ & $1: 30$ \\
\hline \multirow{2}{*}{$1^{\text {st }}$} & Women & 10 & 10 & 10 & 10 & 10 & 10 & 8 & 7 & 7 & 5 & 4 & 3 \\
\cline { 2 - 16 } & Men & 10 & 10 & 10 & 10 & 8 & 7 & 6 & 7 & 7 & 5 & 3 & 5 \\
\hline \multirow{2}{*}{$2^{\text {nd }}$} & Women & 10 & 10 & 10 & 10 & 8 & 7 & 5 & 4 & 8 & 10 & 10 & 10 \\
\cline { 2 - 16 } & Men & 10 & 10 & 10 & 10 & 7 & 5 & 5 & 5 & 9 & 10 & 10 & 10 \\
\hline \multirow{2}{*}{$3^{\text {rd }}$} & Women & 10 & 10 & 10 & 10 & 8 & 8 & 4 & 1 & 9 & 9 & 10 & 10 \\
\cline { 2 - 15 } & Men & 10 & 10 & 10 & 10 & 10 & 9 & 6 & 4 & 8 & 10 & 10 & 10 \\
\hline \multirow{2}{*}{$4^{\text {th }}$} & Women & 10 & 10 & 10 & 10 & 9 & 8 & 5 & 5 & 9 & 10 & 10 & 10 \\
\cline { 2 - 14 } & Men & 10 & 10 & 10 & 10 & 10 & 8 & 6 & 4 & 10 & 9 & 10 & 10 \\
\hline
\end{tabular}

In contrast with the overall acceptance of the environment, the responses to the surface temperatures clearly show that subjects perceived the effects of asymmetric radiation. Even though their discomfort sensation is not reflected by the overall evaluation of the environment, they indicate their dissatisfaction with the increased radiation through the responses given to question no. 5 of the questionnaire. All the subjects who were dissatisfied with the surface temperatures indicated that the temperature of the left-side wall/window should decrease.

\section{Conclusions}

A series of experiments were carried out in order to investigate the thermal comfort sensation under simultaneous asymmetric radiation and elevated air velocity. Skin temperatures of the 
faces and hands were measured, and subjective responses were gathered. The following conclusions can be stated:

- The skin temperature of hands and faces varies differently with gender under an incident asymmetric radiation of $105 \mathrm{~W} \cdot \mathrm{m}^{-2}$. The temperature of the hands of the women decreased, while it remained almost constant for the men. Moreover, the leftand right-side facial temperatures are almost equal in the case of women, while a difference of approximately $0.5 \mathrm{~K}$ was registered between the left and right sides of the face in the case of men.

- There is no significant difference between the calculated PMV value and the mean of the thermal sensation responses given by all subjects for the first two periods of each session. However, the differences between the means of the subjective thermal sensation responses of the analysed groups are significantly different after the second period of each session.

- Shifting the direction of airflow around the head leads to a significantly lower value of subjective thermal comfort sensation than the calculated PMV value.

- The negative effect of asymmetric radiation on the overall acceptance of the environment is not reflected by the responses of subjects. However, at the end of the second period $30 \%-90 \%$ of subjects required a reduction in the left-side surface temperature.

- Elevated air velocity $\left(0.48 \mathrm{~m} \cdot \mathrm{s}^{-1}\right)$ was considered too high by $30 \%-60 \%$ of the subjects (depending on the operation mode of ALTAIR). This air velocity corresponds to the chosen circulated airflow $\left(20 \mathrm{~m}^{3} \cdot \mathrm{h}^{-1}\right)$. By moving the air around the occupants not only the fresh air is assured, but a cooling effect is obtained. Thus, the personalized ventilation system can be considered as a personalized ventilative cooling system.

- When the direction of airflow was changed, the number of subjects who were dissatisfied with air freshness decreased.

Some of the hypothesised effects and relations were confirmed by the performed experiments (the subjective thermal comfort sensation increased in the first hour, and the asymmetric radiation was neutralised by the elevated air speed). However, subjects tolerated the asymmetric radiation and the higher temperatures better than the elevated air speed.

In future, the interrelation between irradiance and elevated air speed according to gender and age will be investigated.

\section{References}

[1] C.K. Chau, E.Y. Tu, D.W.T. Chan, J. Burnett, Estimating the total exposure to air pollutants for different population age groups in Hong Kong, Environment International 27 (2002) 617-630.

[2] Judith A. Leech, William C. Nelson, Richard T. Burnett, Shawn Aaron, Mark E. Raizenne, It's about time: A comparison of Canadian and American time-activity patterns, Journal of Exposure Analysis and Environmental Epidemiology (2002) 12, 427 - 432. 
[3] Sabine Brasche, Wolfgang Bischof, Daily time spent indoors in German homes - Baseline data for the assessment of indoor exposure of German occupants, Int. J. Hyg. Environ.-Health 208 (2005) 247-253.

[4] ISO 7730-2005: Ergonomics of the thermal environment - Analytical determination and interpretation of thermal comfort using calculation of the PMV and PPD indices and local thermal comfort criteria.

[5] P. O. Fanger, B. M. Ipsen, G. Langkilde, B. W. Olesen, N. K. Christensen, S. Tanabe, Comfort limits for asymmetric thermal radiation, Energy and Buildings, 8 (1985) 225 - 236.

[6] Kamel Ghali, Nesreen Ghaddar, Maher Salloum, Effect of stove asymmetric radiation field on thermal comfort using a multisegmented bioheat model, Building and Environment 43 (2008) 1241-1249.

[7] M. Al-Othmani, N. Ghaddar, K. Ghali, A multi-segmented human bioheat model for transient and asymmetric radiative environments, International Journal of Heat and Mass Transfer 51 (2008) 5522-5533.

[8] Tomonori Sakoi, Kazuyo Tsuzuki, Shinsuke Kato, Ryozo Ooka, Doosam Song, Shengwei Zhu, Thermal comfort, skin temperature distribution, and sensible heat loss distribution in the sitting posture in various asymmetric radiant fields, Building and Environment 42 (2007) 3984-3999.

[9] Roman Rabenseifer, Basic types of glazing with low-emissivity and their effects, International Review of Applied Sciences and Engineering, 7 (2016), 45-50.

[10] Ferenc Kalmar, Summer operative temperatures in free running existing buildings with high glazed ratio of the facades, Journal of Building Engineering 6 (2016) 236-242.

[11] Ferenc Kalmar, Interrelation between glazing and summer operative temperatures in buildings, International Review of Applied Sciences and Engineering, 7 (2016), 51-60.

[12] Edward Arens, Tyler Hoyt, Xin Zhou, Li Huang, Hui Zhang, Stefano Schiavon, Modeling the comfort effects of short-wave solar radiation indoors, Building and Environment 88 (2015) 3-9.

[13] Maria La Gennusa, Antonino Nucara, Gianfranco Rizzo, Gianluca Scaccianoce, The calculation of the mean radiant temperature of a subject exposed to the solar radiation-a generalised algorithm, Building and Environment 40 (2005) 367-375.

[14] Maria La Gennusa, Antonino Nucara, Matilde Pietrafesa, Gianfranco Rizzo, A model for managing and evaluating solar radiation for indoor thermal comfort, Solar Energy 81 (2007) 594-606.

[15] G. Rizzo, G. Franzitta, G. Cannistraro, Algorithms for the calculation of the mean projected area factors of seated and standing persons, Energy and Buildings, 7 (1991) 221230.

[16] Shin-ichi Tanabe, Chie Narita, Yoshiichi Ozeki, Masaaki Konishi, Effective radiation area of human body calculated by a numerical simulation, Energy and Buildings 32 (2000), 205-215.

[17] Arens E., Turner S., Zhang H., Paliaga G.: Moving Air For Comfort, ASHRAE Journal May 2009 p. 18-29.

[18] Melikov AK. Advanced air distribution: improving health and comfort while reducing energy use, Indoor Air; 2016, 26: 112-124. 
[19] Hideyuki Amaia, Shin-ichi Tanabe, Takashi Akimoto, Takeshi Genma, Thermal sensation and comfort with different task conditioning systems, Building and Environment 42 (2007) 3955-3964.

[20] Kalmár F. Innovative method and equipment for personalized ventilation, Indoor Air; 2015, 25: 297-306.

[21] Shinichi Watanabe, Toshimichi Shimomura, Hironori Miyazaki, Thermal evaluation of a chair with fans as an individually controlled system, Building and Environment 44 (2009) 1392-1398.

[22] P. O. Fanger, A. K. Melikov, H. Hanzawa, J. Ring, Air Turbulence and Sensation of Draught, Energy and Buildings, 12 (1988) $21-39$.

[23] Barbara Griefahn, Christa Künemund, Ulrike Gehring, The significance of air velocity and turbulence intensity for responses to horizontal drafts in a constant air temperature of 23 ${ }^{\circ} \mathrm{C}$, International Journal of Industrial Ergonomics 26 (2000) 639-649.

[24] Jorn Toftum, Ruth Nielsen, Draught sensitivity is influenced by general thermal sensation, International Journal of Industrial Ergonomics 18 (1996) 295-305.

[25] L.G. Berglund, A.P.R. Fobelets, Subjective human response to low-level air currents and asymmetric radiation, ASHRAE, No. 3044 (RP-353), 497-523.

[26] Charlie Huizenga, Hui Zhang, Pieter Mattelaer, Tiefeng Yu, Edward Arens, Peter Lyons, Window performance for human thermal comfort, Final Report to the National Fenestration Rating Council, February 2006,

[27] Li Lan, Zhiwei Lian, Application of statistical power analysis - How to determine the right sample size in human health, comfort and productivity research, Building and Environment 45 (2010) 1202-1213.

[28] Simon G. Hodder, Ken Parsons, The effects of solar radiation on thermal comfort, Int $\mathbf{J}$ Biometeorol (2007) 51:233-250.

[29] Frédéric Haldi, Darren Robinson, On the unification of thermal perception and adaptive actions, Building and Environment 45 (2010) 2440-2457.

[30] Leaman A., Bordass B., Productivity in buildings: the "killer" variables, Building Research and Information, 1999, 27(1):4-19.

[31] Kalmar F., Investigation of thermal perceptions of subjects with diverse thermal histories in warm indoor environment, Building and Environment 107 (2016) 254-262.

[32] Kollmar A., Liese B., Die Strahlungsheizung, R. Oldenburg, Munich, 1957. 